\title{
DESIGN THINKING (DT) PARA A RESOLUÇÃO DE PROBLEMAS: UM PASSO A PASSO PARA TRABALHAR A EDUCAÇÃO AMBIENTAL (EA) NAS ESCOLAS
}

Ana Carolina de Moraes ${ }^{1}$

Marta Jussara Cremer²

Resumo: A Educação Ambiental deve ser pautada por uma postura dialógica, contextualizada, interdisciplinar e problematizadora para que os temas tratados em ações de educação ambiental tenham uma perspectiva educativa plena, que pode ser alcançada por meio da utilização do Design Thinking (DT). Nos últimos dois anos, uma instituição de ensino superior (IES) realizou diversas formações em Design Thinking, as quais evidenciaram, durante os processos, que sua aplicação não é algo simples. Dessa forma, o objetivo deste artigo é apresentar a funcionalidade do Design Thinking, a partir da problemática: "Como podemos repensar o meio ambiente nas comunidades ao entorno da escola?". Um passo a passo com ideias, ferramentas, exemplos e dicas úteis para o professor.

Palavras-chave: Educação Ambiental; Design Thinking. 


\section{Introdução}

A história tem mostrado que, ao longo das últimas décadas, uma nova consciência acerca das questões relacionadas ao meio ambiente vem emergindo, isso porque, após a percepção de que o meio ambiente é um bem gratuito, a sociedade, por meio de um modo de vida insustentável, comprometeu a estabilidade ambiental.

$\mathrm{Na}$ década de 1970, começaram a se apresentar as questões ambientais. No Brasil, em 1973, através do Decreto no 73.030, de 30 de outubro de 1973, foi criada a Secretaria Especial do Meio Ambiente (SEMA). Já na década de 1980, a Política Nacional do Meio Ambiente, definida por meio da Lei oㅡ 6.938/81, situou a Educação Ambiental, objetivando capacitar estudantes e a comunidade para participação ativa na defesa do meio ambiente.

Por certo, a Política Nacional do Meio Ambiente (PNMA) visa à preservação, melhoria e recuperação da qualidade ambiental propícia à vida, objetivando assegurar no País condições ao desenvolvimento socioeconômico, aos interesses da segurança nacional e à proteção da dignidade da vida humana, atendidos alguns princípios, entre eles, a educação ambiental em todos os níveis de ensino, inclusive a educação da comunidade, objetivando capacitá-la para participação ativa na defesa do meio ambiente (BRASIL, 2015a, grifo nosso).

$\mathrm{Na}$ Constituição de 1988, conhecida como Constituição Cidadã, é que se percebe uma maior valorização da educação ambiental, tendo em vista a sua elevação à condição de direito e relação como ponto fundamental para a busca da qualidade de vida da sociedade. Na Constituição Federal, Título VII, Capítulo VI, artigo 225, todos são convocados a compartilhar ações para o bem comum.

\section{Capítulo VI - MEIO AMBIENTE}

Artigo 225 - Todos têm direito ao meio ambiente ecologicamente equilibrado, bem de uso comum do povo e essencial à sadia qualidade de vida, impondo-se ao Poder Público e à coletividade o dever de defendê-lo e preservá-lo para as presentes e futuras gerações (BRASIL, 1988).

E, para assegurar a efetividade desse direito, incumbe ao Poder Público, entre outras ações, "promover a educação ambiental em todos os níveis de ensino e a conscientização pública para a preservação do meio ambiente" (BRASIL, 1988, grifo nosso).

A educação ambiental no Brasil, após anos de luta dos ambientalistas, começou a ter um certo reconhecimento no cenário nacional na década de 90 . Nessa, o ápice foi a promulgação da Lei 9.795, em 27 de abril de 1999, instituindo a Política Nacional de Educação Ambiental (PNEA), regulamentada Revbea, São Paulo, V. 14, № 2: 47-68, 2019. 
pelo Decreto-Lei no 4.281/2002. A PNEA, em seu artigo 3으, delibera que como parte do processo educativo mais amplo - todos têm direito à educação ambiental, incumbindo às diversas esferas (poder público, instituições educativas, empresas, sociedade, entre outros) promover a EA.

De fato, vários são os conceitos de Educação Ambiental (EA) difundidos na literatura. A EA, para a Política Nacional de Educação Ambiental, é o processo por meio do qual o indivíduo e a coletividade constroem valores sociais, conhecimentos, habilidades, atitudes e competências voltadas para a conservação do meio ambiente, bem de uso comum do povo, essencial à sadia qualidade de vida e sua sustentabilidade. Segundo as Diretrizes Curriculares Nacionais para a Educação Ambiental, a Educação Ambiental se caracteriza como uma dimensão da educação, uma atividade intencional da prática social, que deve imprimir ao desenvolvimento individual um caráter social em sua relação com a natureza e com os outros seres humanos. Também se deve visar à potencialização dessa atividade humana com a finalidade de torná-la plena de prática social e de ética ambiental. Para Ardoin (2009), a EA é afirmação da vida: celebra a alegria da natureza em toda a sua diversidade, inspira interações humanas responsáveis com ecossistemas em pleno funcionamento e estabelece conexões entre as ações de hoje e as consequências de amanhã.

Mais do que conceitos, a efetivação da EA se dá por meio da contextualização, do diálogo e da prática educativa.

\section{A contextualização}

De acordo com Guimarães (2004, p. 31), "trabalhar pedagogicamente a razão (cognitivo) e a emoção (afetivo) são essenciais na motivação dos educandos, mas não são por si só suficientes para moverem os educandos a transformarem as suas práticas individuais e coletivas". Projetos de educação ambiental, na maior parte, tendem a reproduzir práticas voltadas para a mudança comportamental do indivíduo, muita das vezes, descontextualizada da realidade socioambiental em que as escolas estão inseridas, permanecendo assim preso à "armadilha paradigmática". Dessa forma, planejar ações pedagógicas, em que as práticas sejam viabilizadas, tornam-se fundamentais na perspectiva crítica (GUIMARÃES, 2004).

Corroboram Jacobi, Tozoni-Reis e Layrargues,

o mais desafiador é evitar cair na simplificação de que a educação ambiental poderá superar uma relação pouco harmoniosa entre os indivíduos e o meio ambiente mediante práticas localizadas e pontuais, muitas vezes distantes da realidade social de cada aluno (JACOBI, 2003, p. 198).

os temas ambientais devem ser contextualizados, isto é, os temas ambientais mais importantes para os diferentes grupos sociais são aqueles que têm significado social e histórico para 
estes grupos, aqueles que estão presentes na vida concreta das pessoas, ou seja, os temas ambientais locais (TOZONIREIS, 2006, p. 98).

para além de se trabalhar pontualmente questões globais e distantes da realidade, como a redução da camada de ozônio, as queimadas nas florestas tropicais, o comércio do lixo tóxico, a desertificação ou a extinção de espécies, o educador deve priorizar em sua prática a pauta dos problemas locais que afetam as suas comunidades (LAYRARGUES, 1999, p. 2).

De acordo com Layrargues (1999), a Conferência de Tbilisi, primeiro grande evento internacional acerca da educação ambiental e até hoje é uma das principais referências dos educadores ambientais de mundo, lançou uma importante recomendação que diz respeito à estratégia metodológica da ação educativa: a resolução de problemas ambientais locais, que deve se configurar como o elemento aglutinador da construção de uma sociedade sustentável,

surge então a estratégia da resolução de problemas ambientais locais, na busca de uma aproximação do vínculo entre os processos educativos e a realidade cotidiana dos educandos, onde a ação local representa a melhor oportunidade tanto do enfrentamento dos problemas ambientais, como da compreensão da complexa interação dos aspectos ecológicos com os político-econômicos e socioculturais da questão ambiental (LAYRARGUES, 1999, p. 2).

A partir de temas relacionados ao contexto do estudante, busca-se estabelecer um processo dialógico visando tanto à ampliação da compreensão inicial como à intervenção na realidade. Esse processo implica acessar uma verdade que está encoberta por meio da apropriação crítica da mesma (AVANZI, 2004).

\section{O diálogo}

De acordo com Jacobi (2003, p. 197) "o principal eixo de atuação da educação ambiental deve buscar, acima de tudo, a solidariedade, a igualdade e o respeito à diferença através de formas democráticas de atuação baseadas em práticas interativas e dialógicas". Para Jacobi,

trata-se de um aprendizado social, baseado no diálogo e na interação em constante processo de recriação e reinterpretação de informações, conceitos e significados, que podem se originar do aprendizado em sala de aula ou da experiência pessoal do aluno. Assim, a escola pode transformar-se no espaço em que o aluno terá condições de analisar a natureza em um contexto entrelaçado de práticas sociais, parte 
componente de uma realidade mais complexa e multifacetada (JACOBI, 2003, p. 198).

Costa e Pinheiro, e Paulo Freire, defendem o diálogo como fundamental para a formação e existência do próprio homem.

A formação de cidadãos mais críticos depende diretamente das posturas assumidas pela escola. Propor ações que permitam o diálogo reflexivo não é o elemento único, contudo é fundamental para a educação tratada de forma libertadora (COSTA; PINHEIRO, 2013, p. 43).

O diálogo é o encontro entre os homens, mediatizados pelo mundo, para designá-lo. Se, ao dizer suas palavras, ao chamar ao mundo, os homens o transformam, o diálogo impõe-se como o caminho pelo qual os homens encontram seu significado enquanto homens, o diálogo é, pois, uma necessidade existencial (FREIRE, 1979, p. 42).

\section{As práticas educativas}

As pesquisas em educação ambiental revelam lacunas entre a teoria e a prática educacional, tendo em vista as poucas mudanças ocorridas nas práticas realizadas nas escolas. Por certo, tais lacunas podem ser mais facilmente enfrentadas com o uso de metodologias as quais valorizem 0 conhecimento dos educandos e os levem a problematizar a realidade, mediante a observação de um recorte desta e do diálogo entre seus iguais. Assim, permite-se que os educandos interajam com os processos de aula, que tende a ter uma dinâmica diferenciada, considerando os valores culturais, fundamentados nas características locais, e associando os conteúdos ao cotidiano da comunidade urbana/rural em que a escola se insere de maneira contínua, gradativa e interdisciplinar (DIESEL; BALDES; MARTINS, 2017). Ou seja,

na perspectiva da educação ambiental crítica, transformadora e emancipatória, os temas ambientais não podem ser conteúdos curriculares no sentido que a pedagogia tradicional trata os conteúdos de ensino: conhecimentos pré-estabelecidos que devem ser transmitidos de quem sabe (o educador) para quem não sabe (o educando). A educação crítica e transformadora exige um tratamento mais vivo e dinâmico dos conhecimentos, que não podem ser transmitidos de um polo a outro do processo, mas apropriados, construídos, de forma dinâmica, coletiva, cooperativa, contínua, interdisciplinar, democrática e participativa, pois somente assim pode contribuir para o processo de conscientização dos sujeitos para uma prática social emancipatória, condição para a construção de sociedades sustentáveis (TOZONI-REIS, 2006, p. 97). 
Desse modo, a Educação Ambiental deve ser pautada por uma postura dialógica, contextualizada, interdisciplinar e problematizadora, relacionada ao pensamento crítico e à participação do cidadão ao longo da vida. Somente assim, os temas mais comumente tratados nas propostas educativas ambientais como recursos hídricos, resíduos sólidos, desmatamento, queimadas, mata ciliar, extinção das espécies animais, entre outros, terão uma perspectiva educativa plena. Isto é, a partir do processamento das informações sobre esses temas, educadores e educandos, participativo e coletivamente, buscam empreender reflexões acerca dos conflitos que emergem dos condicionantes históricos, políticos, sociais e culturais dos problemas e soluções ambientais (TOZONI-REIS, 2006).

Para que se tenha uma perspectiva educativa plena, em que se trabalha de forma coletiva e participativa, Moran (2018) descreve que as metodologias ativas apontam caminhos: é preciso envolver mais os alunos, torná-los mais protagonistas, aprender experimentando. Para isso, existem mil formas de mobilização dos educandos que fazem sentido, as quais dão resultados imediatos, que mexem com as aulas convencionais.

Pensando nisso, uma instituição de ensino superior (IES), realizou, nos últimos dois anos, diversas formações em Design Thinking (DT), uma metodologia centrada no ser humano que acelera a inovação e soluciona problemas complexos. A referida IES atua há quase 60 anos na cidade de Joinville/SC e em diversos segmentos: ensino fundamental, médio, técnico, graduação, pós-graduação lato sensu e stricto sensu, com cursos de extensão e capacitação empresarial, e cursos de graduação superior e/ou tecnológico na modalidade de Educação a Distância.

De forma participativa, as formações sempre ocorreram. E durante esse processo, na medida em que a formadora explicava as etapas, os professores colocavam em prática. No entanto, ficou evidenciado, durante as formações, que a aplicação do DT não é algo simples.

Fundamentado nesse processo, o objetivo deste artigo é apresentar a funcionalidade do Design Thinking. A partir da problemática: "Como podemos repensar o meio ambiente nas comunidades ao entorno da escola?". A fim de se alcançar o resultado, será desenvolvido o design thinking, um passo a passo, com ideias, ferramentas, exemplos e dicas úteis para o professor. É preciso deixar claro que as etapas descritas não devem ser encaradas como um modelo rígido a ser seguido, pois observam-se, na literatura, diversas adaptações e até mesmo variedades na abordagem do DT.

\section{Design Thinking (DT)}

Design Thinking é um modelo mental que engloba o pensamento pluralista e o pensamento sistêmico, no intuito de construir futuros melhores. Por certo, ele não é uma caixinha mágica de soluções para problemas, não segue um pensamento linear e não pode ser extremamente simplificado, ou pode perder o seu valor. Na prática, o DT é uma abordagem centrada no ser Revbea, São Paulo, V. 14, № 2: 47-68, 2019. 
humano que acelera a inovação e soluciona problemas complexos. Ao baixar as barreiras da hierarquia e do pensamento exclusivamente cartesiano, o DT oferece espaço para as ideias emergirem sem pré-julgamentos, fazendo com que o nosso cérebro seja forçado a sair da sua zona de conforto, e, a partir daí, enxergar futuros desejáveis (ECHOS, 2016).

Em uma sociedade tecnológica, precisamos pensar em novas escolhas, em novos futuros que consigam responder a complexidade do mundo. Pois pensar e agir da mesma maneira como agimos há 100 anos atrás, não vai nos levar a futuros diferentes. Diante dessa necessidade de crescimento, o DT propõe uma nova maneira de pensar, fundamentado em 3 grandes valores: empatia, colaboração e experimentação (ECHOS, 2016). A Figura 1 apresenta alguns dos inúmeros pontos positivos de utilizar o DT.

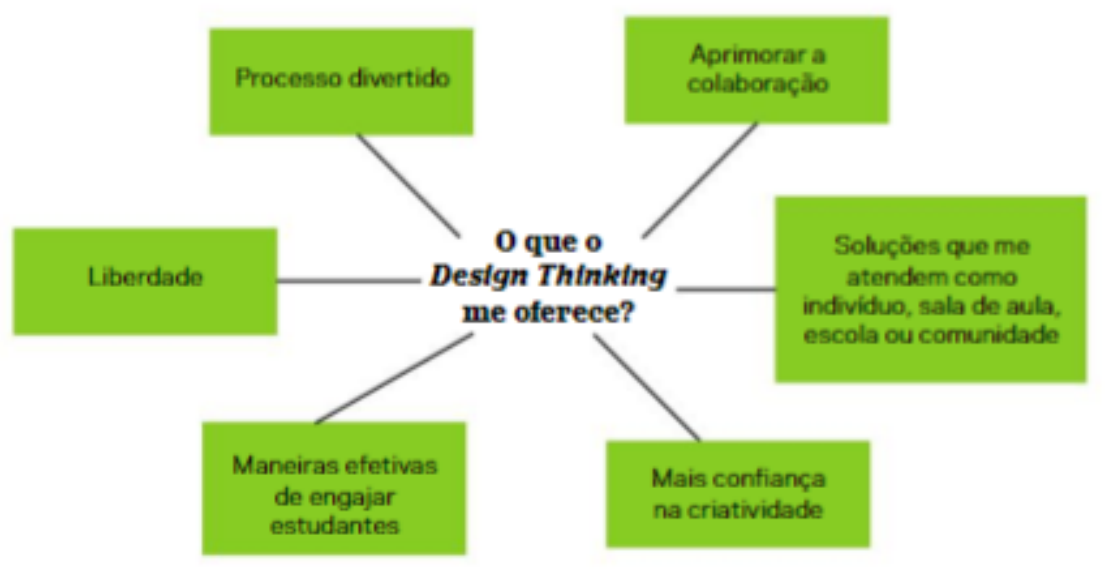

Figura 1: Razões para utilizar o Design Thinking.

Fonte: Educadigital (2018).

Como abordagem, o DT explora as capacidades que todos temos, contudo são negligenciadas por práticas mais convencionais de solução de problemas. Esse mecanismo não se concentra apenas na criação de produtos e serviços centrados no ser humano, mas o processo em si também é profundamente humano. Devido a isso, o processo de design thinking é melhor pensado como um sistema de sobreposição de espaços, em vez de uma sequência de etapas ordenadas. Existem três espaços para manter em mente: inspiração, ideação e implementação. Pense na inspiração como o problema ou a oportunidade que motiva a busca de soluções; ideação como o processo de gerar, desenvolver e testar ideias; e implementação como o caminho que leva da fase do projeto para a vida das pessoas (BROWN; WYATT, 2010).

Para os autores supracitados, a razão para chamar esses espaços, em vez de passos, ocorre pelo fato de nem sempre serem realizados sequencialmente. Os projetos podem passar por inspiração, ideação e implementação mais de uma vez, enquanto a equipe refina suas ideias e explora novas direções. 


\section{Ativando a sala de aula: a funcionalidade do Design Thinking}

Para contextualizar a aplicação do Design Thinking criou-se a Comunidade Babitonga ${ }^{3}$, localizada no município de São Francisco do Sul/SC, representada pela estrela amarela na Figura 2. A comunidade Babitonga fica aos arredores da BR-280 e perto do porto do município, possui uma escola estadual, uma unidade de saúde, supermercados, farmácias, lojas e 540 habitantes.

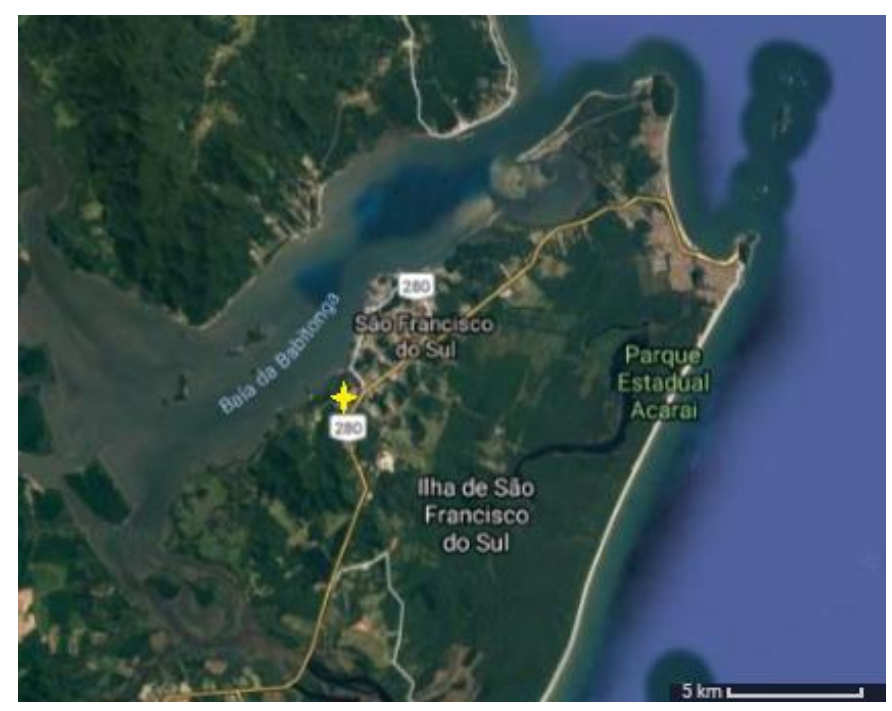

Figura 2: Localização da Comunidade Babitonga. Fonte: TerraMetrics/GoogleMaps (2018).

Embora Brown e Wyatt (2010) não caracterizem como etapas e sim como espaços, na literatura o Design Thinking possui diversas abordagens e nelas estão inclusas as etapas, e, dependendo do autor pesquisado, o processo pode ser trabalhado de três até sete etapas, mas independente de número de etapas, todos realizam as mesmas ações. A abordagem utilizada aqui terá cinco momentos, Figura 3 , inclusas nos três espaços citados por Brown e Wyatt (2010). As ações realizadas nas cinco etapas foram adaptadas de três referências: ECHOS (2016); Vilaça (2018) e Brown e Wyatt (2010).

${ }^{3}$ A comunidade, seus dados, bem como sua localização e o nome da escola, são fictícios. 


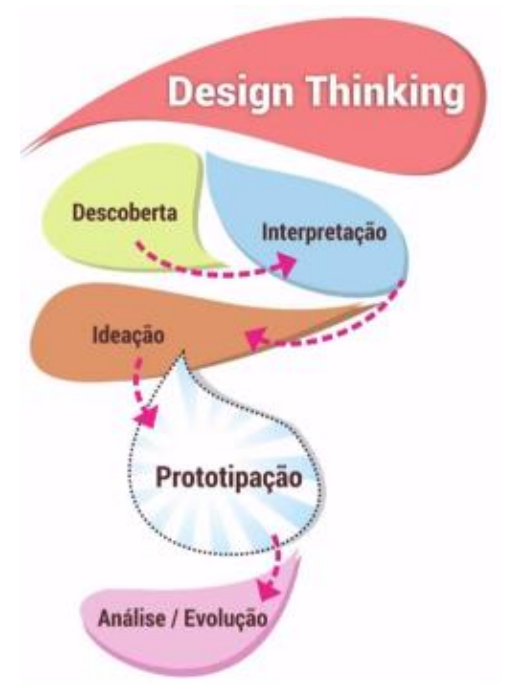

Figura 3: Etapas do Design Thinking.

Fonte: Vilaça (2018).

\section{Inspiração}

No primeiro espaço do Design Thinking, a equipe deverá descobrir quais são as necessidades das pessoas. Formas tradicionais de fazer isso, como grupos de foco e pesquisas, raramente produzem insights importantes. $\mathrm{Na}$ maioria dos casos, essas técnicas simplesmente perguntam às pessoas o que elas querem. Henry Ford entendeu isso quando disse: "Se eu perguntasse a meus clientes o que eles queriam, eles teriam dito 'um cavalo mais rápido' ". Embora as pessoas, muitas vezes, não possam nos dizer quais são suas necessidades, seus comportamentos reais podem fornecer-nos pistas valiosas sobre a sua gama de necessidades não satisfeitas (BROWN; WYATT, 2010). Aqui na inspiração serão abordadas duas etapas: Descoberta e Interpretação.

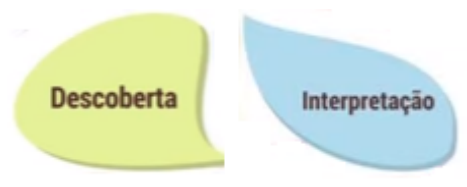

Iniciando o processo:

No Design Thinking, um desafio é o ponto de partida para o processo de design, e o propósito pelo qual você irá trabalhar. O professor lançará então uma pergunta mais ampla. Por exemplo: "Como podemos repensar o meio ambiente nas comunidades ao entorno da escola?". Com base nessa pergunta, os estudantes buscam um primeiro entendimento sobre o tema, caracterizando, assim, a fase da descoberta.

Sugere-se o uso de uma ferramenta chamada CoCo, Figura 4, distribuída pelo grupo Echos. Nessa ferramenta, os estudantes debatem e descrevem o que eles compreendem sobre o tema, e o que eles gostariam de 
conhecer. Todos os estudantes do grupo darão suas primeiras opiniões sobre a temática. Desse modo, para que a prática seja mais dinâmica, o uso de post-its mostra-se muito interessante, uma vez que todos os membros da equipe inserem post-its coloridos sobre o que eles compreendem na coluna da esquerda e sobre o que eles querem conhecer na coluna da direita. $O$ professor, neste momento, deve intervir, solicitando que os estudantes percebam as inúmeras possibilidades as quais rodeiam o termo meio ambiente.

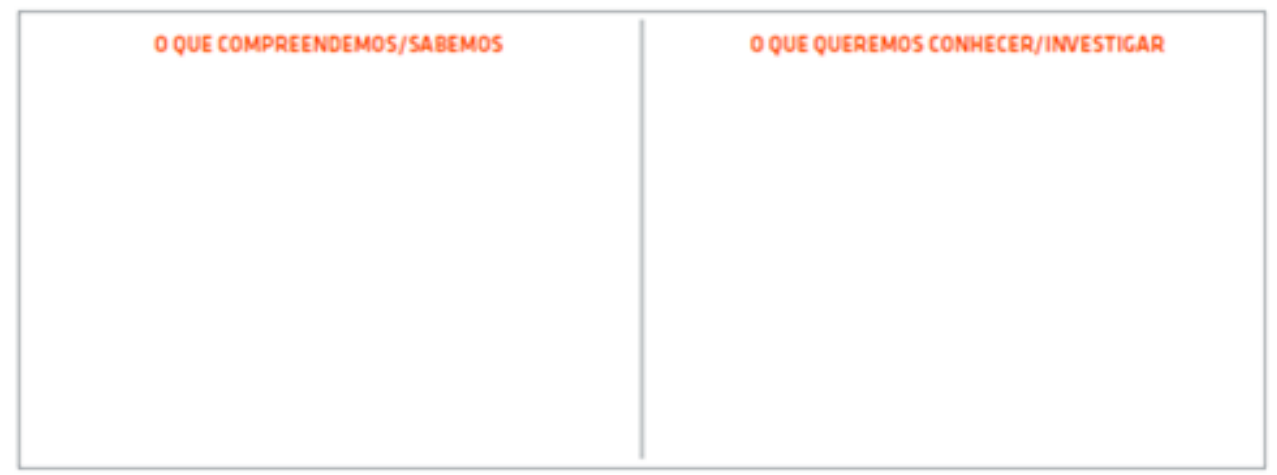

Figura 4: Ferramenta CoCo para a fase de descoberta.

Fonte: Adaptado de ECHOS (2016).

Após o preenchimento da ferramenta CoCo, os estudantes debatem sobre o que sabem e analisam todos os post-its sobre o que querem conhecer. Nesta análise, eles observarão que existem inúmeras possibilidades de se trabalhar com a pergunta sugerida pelo professor. No exemplo: "Como podemos repensar o meio ambiente nas comunidades ao entorno da escola?", os estudantes podem ter colocado nos post-its uma série de respostas sobre 0 que eles querem conhecer/investigar. A partir da leitura de todas as colocações, os estudantes selecionarão os itens que mais se destacaram, ou aqueles de maior interesse da equipe (Figura 5).

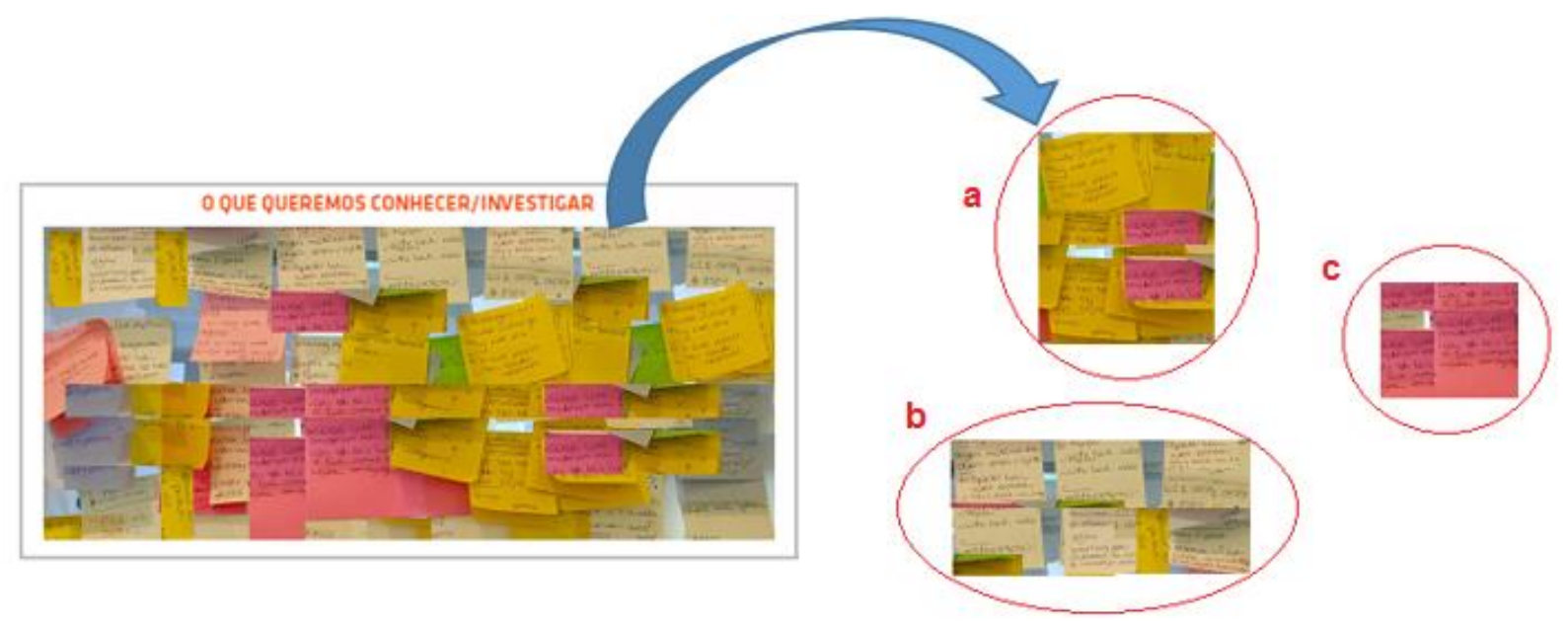

Figura 5: Seleção dos interesses da equipe para ir à campo. Fonte: As autoras (2018).

Revbea, São Paulo, V. 14, № 2: 47-68, 2019. 
Suponha que, nos post-its selecionados, estejam os seguintes comentários/problemáticas, Figura 6.

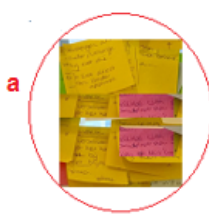

Lixo

Coleta de lixo

Coleta seletiva de lixo

Lixo nas ruas

Lixo no rio ao lado da escola

População não entende porque não

deve jogar lixo no rio

No centro não tem lixo nas ruas

Doenças

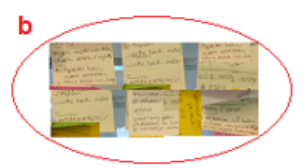

Muitos caminhões ao redor da escola

Sujeira das cargas dos caminhões

Fumaça dos caminhões

Caminhoneiros almoçando nas calçadas

ao redor da escola

Buzinas em excesso

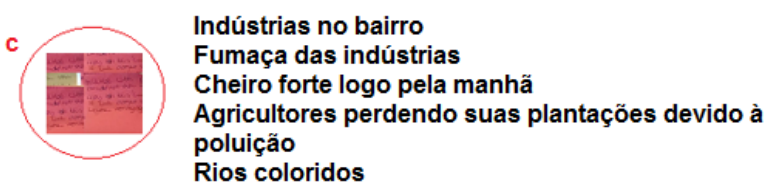

Figura 6: Principais problemáticas incluídas pela equipe.

Fonte: As autoras (2018).

Dependendo do tempo e da disposição da equipe, eles poderão ir a campo buscar entender as três problemáticas (a), (b) e (c). Vamos tomar como exemplo a problemática (b). Os estudantes querem investigar o excesso de caminhões ao redor da escola, a sujeira gerada pelas cargas dos caminhões, além da fumaça e das buzinas em excesso. Esses discentes também querem saber por que os caminhoneiros almoçam nas calçadas ao redor da escola.

A partir do que os estudantes querem investigar, eles devem buscar alguns entendimentos fazendo uma pesquisa sobre as tematicas envolvidas no problema, além disso, devem preparar sua saída à campo. Na saída a campo, os pesquisadores devem realizar uma triangulação da pesquisa, ou seja, ver/observação (olhar etnográfico), ouvir (entrevista) e sentir/participação (Figura 7).

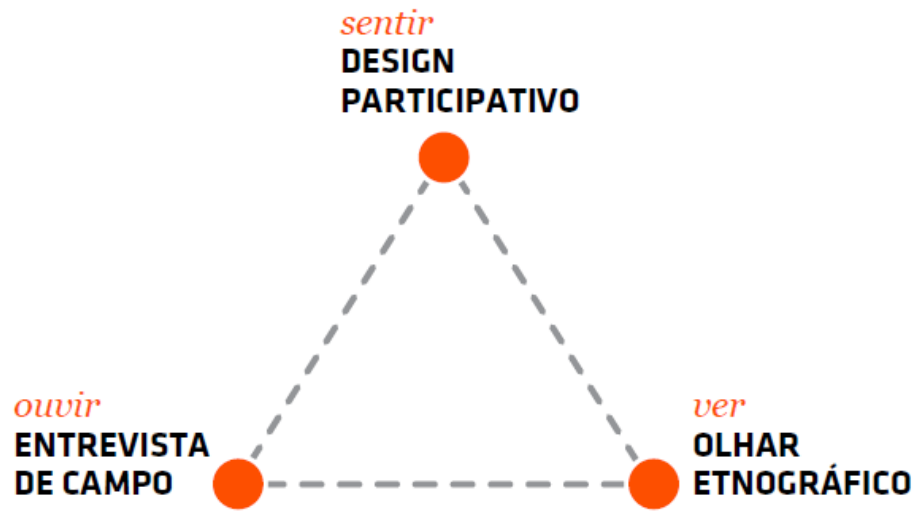

Figura 7: Triangulação da pesquisa.

Fonte: ECHOS (2016). 
A Figura 8 apresenta alguns caminhos para a triangulação da pesquisa.

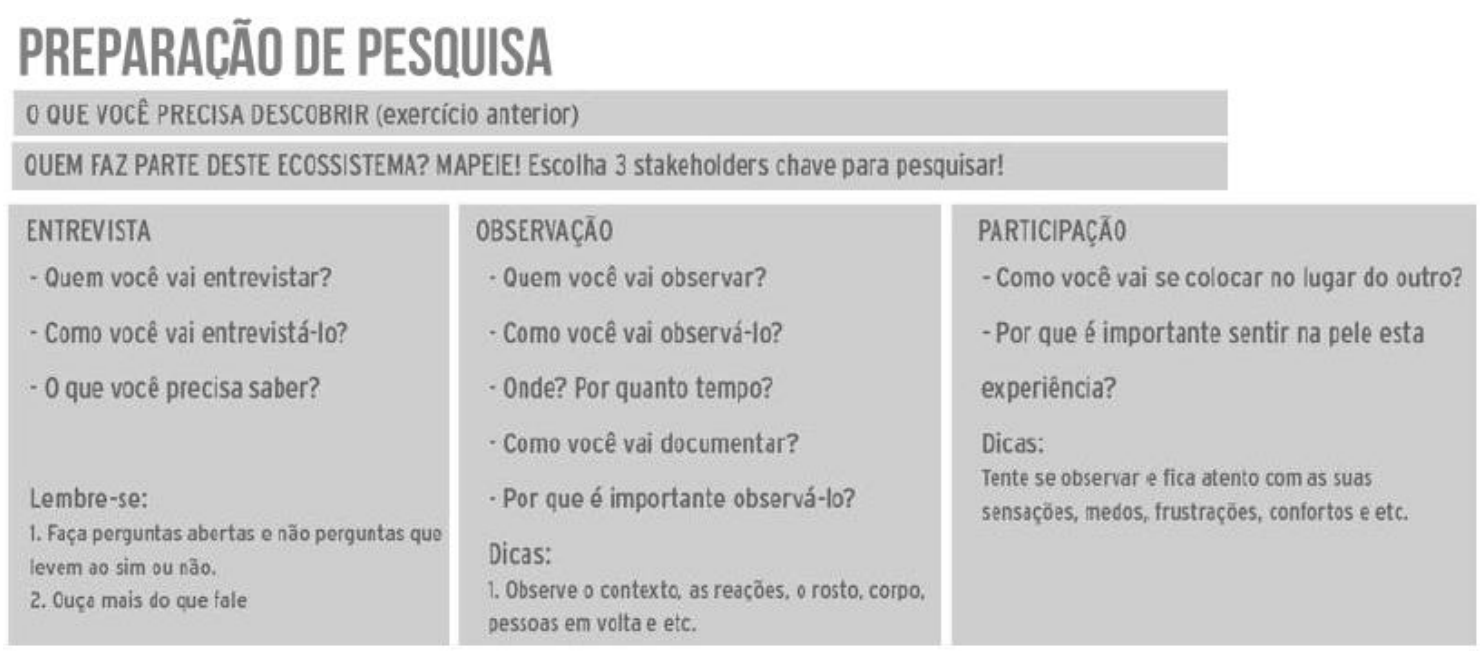

Figura 8: Como preparar a saída de campo. Fonte: ECHOS (2016).

Para a entrevista, eles devem selecionar algumas pessoas, neste caso, poderiam ser: um caminhoneiro (para identificar o porquê de almoçar na calçada e o excesso de buzinas), um morador da comunidade (para identificar os problemas dos grãos nas vias), um representante do município (para identificar se existe algum projeto para minimizar essa problemática), um agente de limpeza urbana (a fim de saber o tempo que ele gasta limpando esses grãos em excesso), um agente de saúde (para identificar os problemas do excesso de buzina e dos grãos nas ruas), entre outros. Aqui são dados apenas alguns exemplos, para que os estudantes possam selecionar alguns deles. Na Figura 9, apresentam-se algumas dicas úteis para a entrevista.

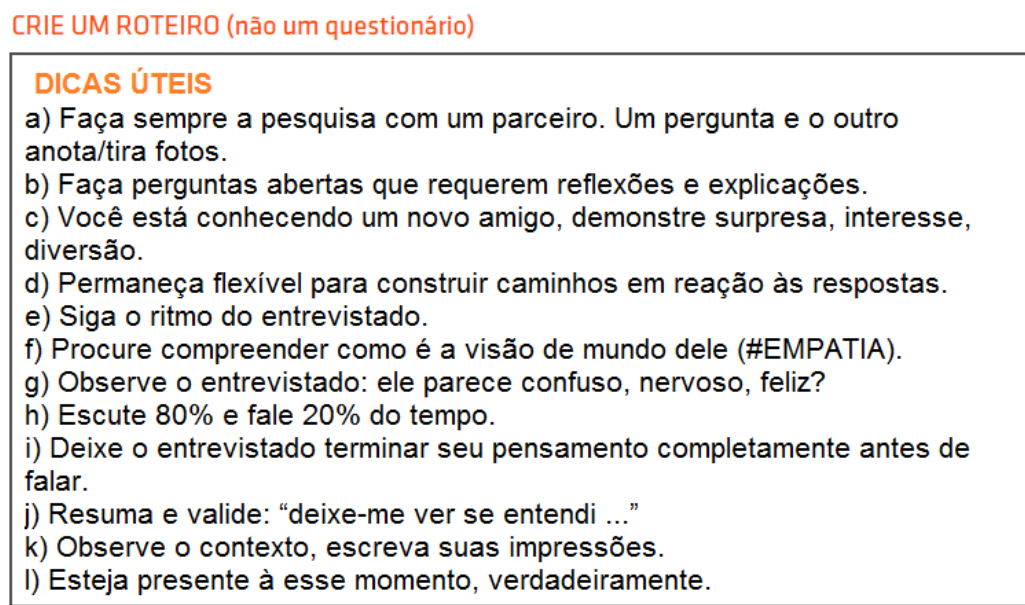

Figura 9: Dicas úteis para elaboração de um roteiro de entrevista.

Fonte: Adaptado de ECHOS (2016). 
Durante a observação, discretamente, no contexto em que os estudantes estão pesquisando, eles devem escolher uma pessoa para analisar e seguir. Por certo, os alunos devem tomar cuidado para não assustar ou influenciar essa pessoa. A princípio, devem acompanhar a pessoa durante um tempo, aproximadamente uns 10 minutos, ou ao longo da jornada que ela fizer dentro do contexto. Observar fatos, coisas, reações. Cabe ao professor, também, informar os seus alunos para não interpretarem o que eles veem, se uma coisa é boa ou ruim, legal ou não. Eles devem se preocupar apenas com os fatos observáveis, anotar as observações para o compartilhamento. Ainda, para melhor análise, permite-se aos alunos tirarem fotos que ilustrem bem as observações relevantes para descrever a experiência observadas (ECHOS, 2016). Já na participação, os estudantes poderiam, por exemplo, almoçar um dia na calçada, ficar duas horas sentados em algum local escutando o excesso de buzinas, rodeados pelos grãos da via, além de varrer a calçada ao entorno da escola e ver quanto tempo a calçada volta a ficar suja. Nesta parte da triangulação da pesquisa, os estudantes podem se dividir, assim, em uma equipe de seis pessoas, duas delas entrevistam, duas observam e duas participam.

Na volta da triangulação da pesquisa, os alunos já ouviram, já sentiram e já observaram alguns dos envolvidos na problemática. Além disso, já fizeram suas pesquisas acerca das temáticas envolvidas. Então, chegou a hora da interpretação!

Agora é necessário sintetizar o que foi aprendido e reformular o problema em termos de necessidades das pessoas entrevistadas. Voltemos à pergunta inicial: "Como podemos repensar o meio ambiente nas comunidades ao entorno da escola?". Os estudantes pesquisaram e foram para campo investigar por que os caminhoneiros almoçam nas calçadas ao redor da escola, o excesso de caminhões ao redor da escola, a sujeira gerada pelas cargas dos caminhões, além da fumaça e as buzinas em excesso. Vilaça (2018) descreve que a equipe deverá se questionar: que os dados coletados nos dizem? Por que nossas pesquisas e experiências foram úteis para entender melhor 0 problema? Quais são os reais problemas das pessoas entrevistadas? Que realmente nós conseguimos solucionar? Diante disso, para a próxima fase, a equipe deverá selecionar uma necessidade específica a ser solucionada, ou seja, a equipe deverá buscar um foco a ser pesquisado. Aqui, é importante elaborar uma nova pergunta com foco nas necessidades das pessoas entrevistadas.

A partir da síntese, eles perceberam um problema real a ser trabalhado. Na verdade, eles perceberam vários problemas, mas selecionarão um deles (aqui, novamente, tudo irá depender do tempo e da disposição da equipe). 
Problema real percebido pelos estudantes

Os estudantes saíram a campo e fizeram a triangulação da pesquisa na comunidade Babitonga. Eles já sabem que São Francisco do Sul é uma cidade portuária, e que o porto é fundamental para a história e economia do município. Durante a pesquisa, os estudantes foram entender por que existem tantos grãos na rodovia e souberam que os grãos são a principal natureza de carga do Complexo Portuário de São Francisco do Sul. Ao entrevistar os moradores da comunidade Babitonga, esses relataram que um dos principais problemas ambientais da comunidade era o adensamento das empresas de retaguarda do porto, que causa um desequilíbrio, resultando em proliferação de vetores transmissores de doenças (algumas crianças já estavam ficando doentes), contaminação da água de rios, entupimento do sistema de drenagem pluvial, frequentemente ocasionadas pelo derramamento de grãos.

Então, de tudo o que os estudantes investigaram, identificaram que a comunidade "Babitonga" adoecia devido à poluição gerada pelos grãos que caiam em excesso dos caminhões; a partir daí, um novo problema deve ser reformulado em termos de necessidades das pessoas entrevistadas: "Como minimizar os impactos gerados pelos grãos e melhorar a saúde da comunidade Babitonga?".

\section{Ideacão}

O segundo espaço do processo de design thinking é a ideação. Depois de passar algum tempo no campo, observando e fazendo pesquisas, a equipe reformulou a pergunta, definindo um foco, agora, por meio de várias ideias, buscam por soluções ou oportunidades de mudança. Neste espaço, apenas uma etapa será trabalhada: a própria ideação.

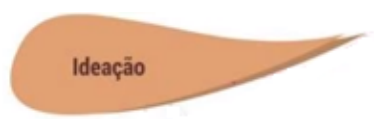

Iniciando o processo:

A ideação é um momento de criar muitas ideias de possíveis soluções para o problema, aqui quantidade é melhor que qualidade, todas as ideias são bem-vindas, sem julgamentos e restrições. A ideação ocorre em dois momentos. Primeiramente, de forma individual, cada estudante coloca em postits suas propostas para resolução do problema; e, posteriormente em equipe, utiliza-se a técnica de brainstorming, que é uma técnica colaborativa para estimular a geração de um grande número de ideias em um curto espaço de tempo, respeitando as regras apresentadas na Figura 10. 


\section{REGRAS DE BRAINSTORMING}

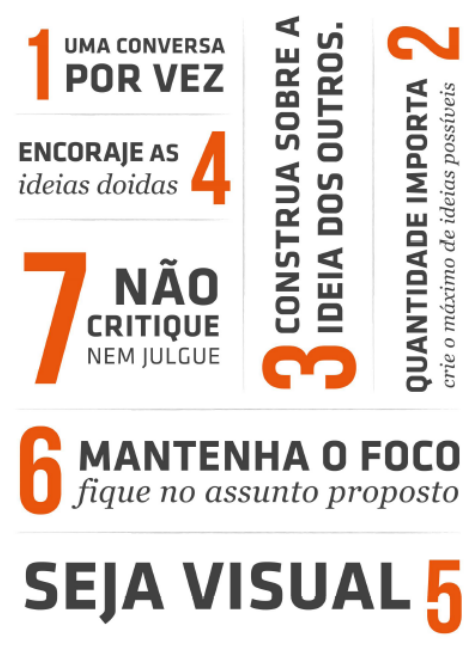

Figura 10: Regras da técnica de brainstorming. Fonte: ECHOS (2016).

Assim, as equipes realizam a técnica de brainstorming, e surgem daí várias ideias para resolução do problema da comunidade "Babitonga". É importante que as equipes falem e anotem todas as ideias em post-its, para que, após a finalização do brainstorming, as equipes agrupem ideias que se complementem, as quais se relacionem, ou que não, mas que, após a análise, a equipe acredite que, unindo duas (ou mais) ideias, nasça uma potencial solução (Figura 11).

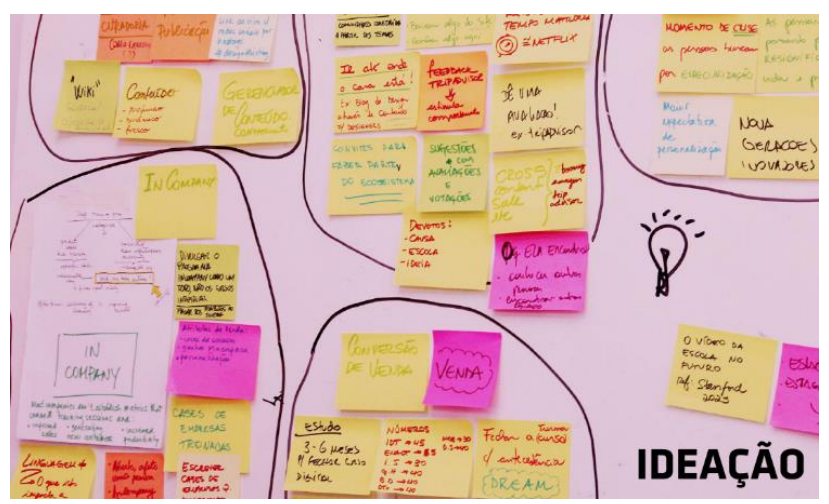

Figura 11: Agrupamento das principais ideias. Fonte: ECHOS (2016).

Posteriormente, os estudantes devem selecionar as melhores ações para resolver o problema a fim de ir para a próxima etapa, a de prototipagem. De acordo com Vilaça (2018), antes de seguir à próxima etapa, a equipe deve responder a seguinte pergunta: Por que estas ideias foram escolhidas e outras não? É preciso conseguir responder esta pergunta e, somente depois, ir para a próxima etapa. 


\section{Implementação}

O terceiro espaço do processo de design thinking é a implementação, em que, no centro do processo, está a prototipagem, transformando ideias em produtos e serviços reais que são testados, iterados e refinados. Por meio da prototipagem, o processo de design thinking procura descobrir desafios imprevistos de implementação e consequências não intencionais para obter um sucesso mais confiável a longo prazo. Aqui na implementação, serão abordadas duas etapas: a prototipação e a análise/evolução.

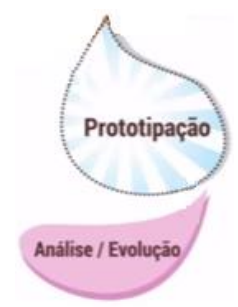

Iniciando o processo:

As equipes foram para a fase de prototipação com algumas ideias a fim de solucionar o problema da comunidade "Babitonga". Agora, a equipe deve prototipar cada uma dessas ideias (aqui volta a questão do tempo e a disposição da equipe, para testar uma ou todas as ideias que tiveram). A prototipagem auxilia a tangibilizar e a validar ideias, portanto, as equipes devem ser criativas, pensar nos materiais e nos detalhes do protótipo, que podem ser bonecos, cartazes, maquetes, encenações, como mostra a Figura 12.

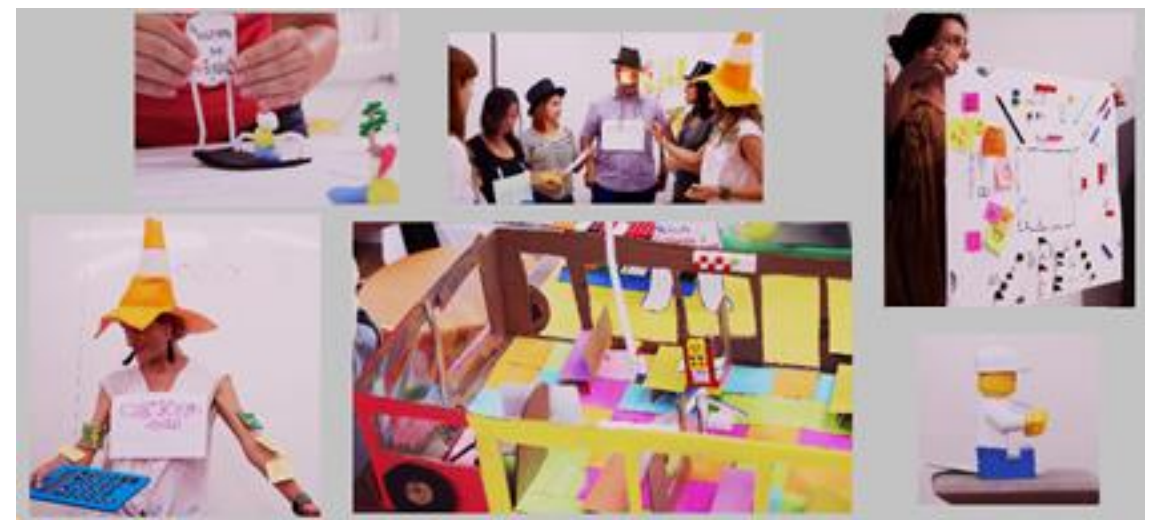

Figura 12: Exemplos de protótipos.

Fonte: Adaptado de ECHOS (2016).

Com o(s) protótipo(s) pronto(s), chegou a hora da análise/evolução. Neste momento, os estudantes voltam ao campo para mostrar o(s) protótipo(s) e apresentar as ideias aos participantes lá da triangulação da pesquisa. Em nosso exemplo, "Como minimizar os impactos gerados pelos grãos e melhorar a saúde da comunidade Babitonga?", os estudantes voltam à comunidade Babitonga e apresentam os protótipos (Figura 13). 


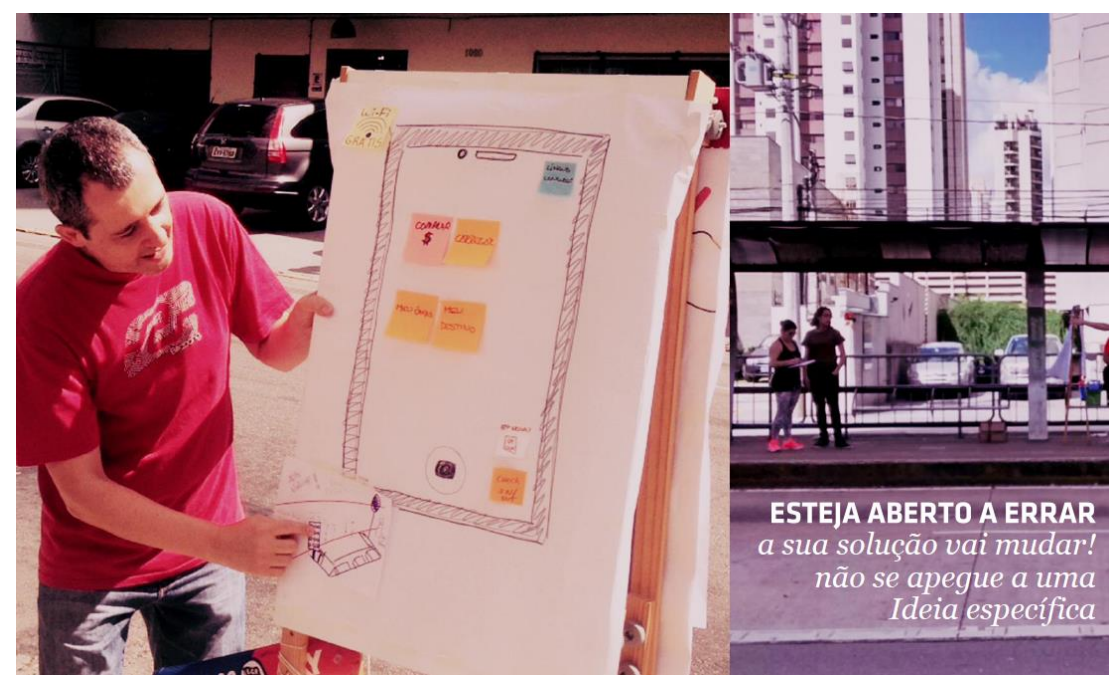

Figura 13: Apresentação do protótipo na comunidade.

Fonte: ECHOS (2016).

Neste momento, sugere-se uma nova ferramenta, o feedback do teste, apresentado na Figura 14. Os estudantes apresentarão o(s) protótipo(s) para alguns representantes da comunidade e anotarão os pontos bem avaliados, os pontos a melhorar, o maior diferencial e as sugestões.

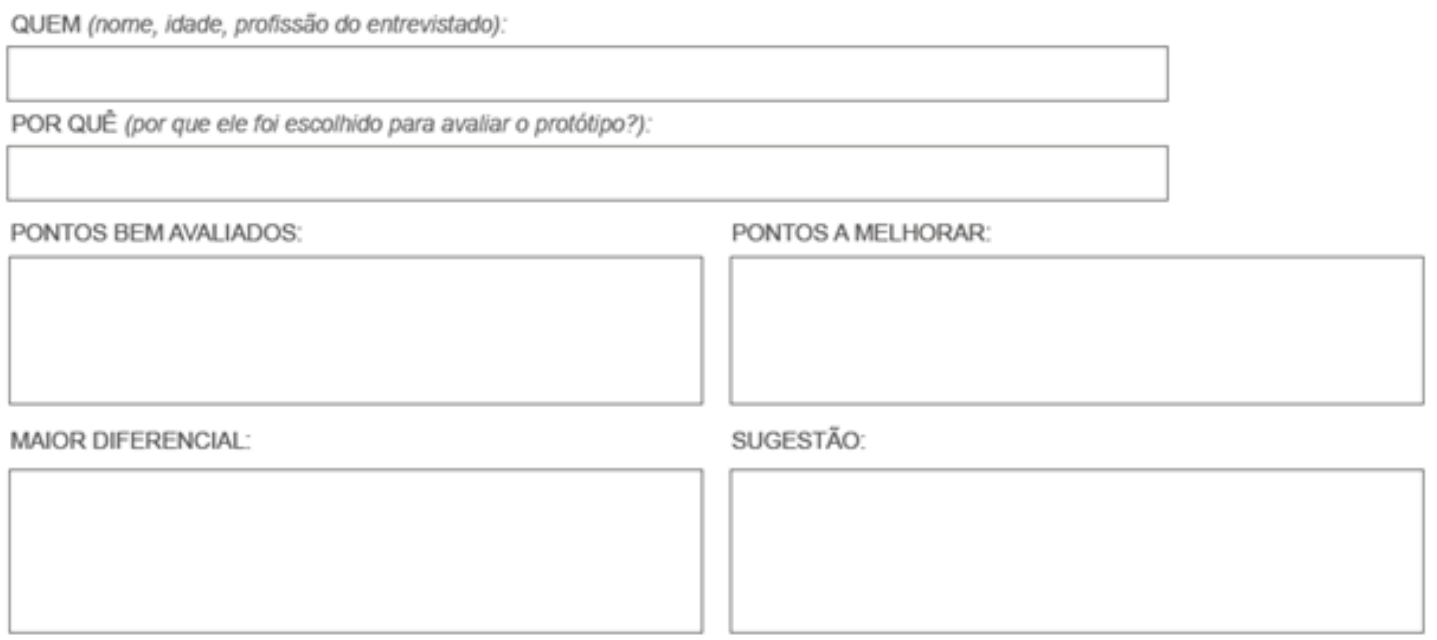

Figura 14: Ferramenta Feedback do teste. Fonte: Adaptado de ECHOS (2016).

Com base em todas as respostas, os estudantes melhorarão o(s) protótipo(s), adequando às necessidades propostas pela comunidade. Assim, o protótipo vai se completando, na medida em que a comunidade apresenta sugestões.

Por fim, uma apresentação do protótipo é realizada para a classe. Que tal fazer uma apresentação aberta à comunidade? Ou, que tal entregar o 
protótipo, com as possíveis soluções para o problema da comunidade "Babitonga" para um representante legal da comunidade? É preciso dar vida ao protótipo, afinal, reveja por quantas etapas você passou para chegar até aqui!

\section{Alguns caminhos para melhoria do processo do Design Thinking A formação da equipe}

O número de integrantes de cada equipe dependerá do número de estudantes participantes do processo. Para que as ações sejam cumpridas, é interessante nomear, em cada grupo, um líder. A função do líder é garantir que a discussão do problema se dê cumprindo todos os passos da metodologia utilizada, e que todos os membros do grupo participem da discussão.

Aqui, o professor poderá, inclusive, abordar a importância da gestão de equipes. Expondo, então, que o perfil de liderança está representado pela figura do líder que sabe ouvir, dialogar, tem empatia com as equipes, humildade; possui entusiasmo, sabe gerir conflitos e o tempo. É importante que o líder se altere em cada aplicação do DT. Cabe ressaltar, também, que, na vida adulta, os estudantes nem sempre trabalharão com pessoas que fazem parte do seu círculo de amizades, então, a fim de desenvolver habilidades de relações interpessoais, seria justo realizar um sorteio para selecionar as equipes, ou o professor escolher com base em critérios pré-definidos.

\section{O papel do aluno e do professor}

Aqui no DT, o aluno é, efetivamente, um protagonista, pois, durante as aulas, são desenvolvidas estratégias em que o aluno necessita perguntar, responder, aplicar, expor análises e as próprias conclusões. A aula, por ser desafiadora, propositiva, intrigante, faz com que os alunos, em grupos, sejam instigados a interrogar, sugerir, classificar, simbolizar, propor e buscar soluções. Assim, a cada momento, o aluno é agente construtor do seu próprio processo de aprendizagem (ANTUNES, 2014). Além disso, esse deve a todo momento contribuir com a equipe para o alcance uma meta comum, o que envolve o pensamento crítico e a tomada de decisões sobre como e o que aprender.

Já o grande desafio para os professores é ajudar a desenvolver, nos alunos, a capacidade do trabalho autônomo, colaborativo e o senso crítico, que não se desenvolve por meio de monólogos expositivos; e sim, pelo diálogo, no confronto de ideias e de práticas, na capacidade de ouvir, ouvir-se, e se autocriticar (ALARCÃO, 2011). O papel do professor é de facilitador, mentor, orientador, mediador, que deve, conforme Vallim (2008), Sousa (2011) e Antunes (2014):

- Usar o seu conhecimento não no sentido de transmiti-los diretamente aos estudantes, mas para ajudá-los a evitar seguirem caminhos improdutivos e se dispersarem em detalhes irrelevantes. 
- Cuidar para que os grupos não caiam no erro de encontrar explicações simplistas e superficiais que levariam a soluções que não exploram adequadamente os objetivos de aprendizagem contidos no problema.

- Estimular o pensamento crítico e o autoaprendizado.

- Ajudar o aluno a organizar, ampliar e aprofundar os saberes que traz consigo.

- Estimular ideias, propor desafios, interrogar, debater, arquitetar problemas e estimular os alunos na pesquisa e descoberta.

- Ser crítico na proposição de desafios e encaminhamento de processos de procura, sabendo sempre que "ninguém ignora tudo, ninguém sabe tudo".

- Mediar, ajudar o aluno a criar associações e experimentações, e, sobretudo, rejeitar a ideia do erro como um tropeço, preferindo destacála como um trampolim na rota da aprendizagem.

\section{A avaliação}

A avaliação deve ser contínua, progressiva, não representando um instrumento de propriedade do professor que se aplica ao aluno. Mas estímulos à autoavaliação na qual o aluno, após um desafio, é instigado a perceber seu progresso, sua evolução. Lembrando que não existe progresso se não houver um objetivo claro, assim, a conquista do progresso ganha sentido quando comparada com os objetivos traçados e quando se mostra ou não esse alcance (ANTUNES, 2014).

Dois pontos importantes: a ideia de avaliação contínua no processo de ensino e aprendizagem é a atenção e ocupação permanente do professor com a apropriação efetiva do conhecimento por parte do aluno, com a interação aluno-objeto do conhecimento-realidade; é uma postura, um compromisso durante todo o processo. Já a autoavaliação é importante, na medida em que ajuda 0 aluno a se localizar no processo de ensino e aprendizagem, possibilitando a metacognição (o conhecimento sobre o caminho de conhecimento que está percorrendo), além de favorecer o desenvolvimento da autorregularão, da autonomia. Por meio dela, o estudante pode assumir responsabilidade pelo próprio desenvolvimento, perceber o erro e buscar formas de superação, assumir a necessidade de mudar a sua participação em sala, os relacionamentos, a maneira de tratar suas dificuldades, a forma de estudo em casa, entre outros (VASCONCELLOS, 2006).

Importante destacar que, como no DT um protótipo é solicitado, segundo Sousa (2011), o professor deve ser bastante criterioso para não incidir no erro de se encantar por um produto final muito bem realizado por um grupo e invalidar o processo de outro grupo que não tenha tido tanto êxito. Ao acompanhar o processo, é possível ao professor verificar se um ótimo produto final é também resultante de um processo muito bem realizado, ou ainda, se um produto final mediano significa que o processo também foi mediano. 


\section{O planejamento}

A seguir, no Quadro 1, uma proposta de planejamento para aplicação do Design Thinking em seis aulas de $45 \mathrm{~min}$, excluindo-se as saídas a campo. Lembrando que a abordagem é flexível, a distribuição do tempo das ações pode ser alterada, bem como adaptações podem ser realizadas.

Quadro 1: Proposta de planejamento para aplicação do Design Thinking.

\begin{tabular}{|l|c|}
\hline Ação & Tempo (min) \\
\hline 1) Explicar metodologia e indicar o tema por meio de uma pergunta abrangente. & 20 \\
\hline 2) Preenchimento do CoCo. & 25 \\
\hline 3) Seleção de itens para investigação. & 20 \\
\hline 4) Preparação da pesquisa. & 25 \\
\hline 5) Saída à campo. & - \\
\hline 6) Síntese e formulação do novo problema. & 25 \\
\hline 7) Ideação individual. & 5 \\
\hline 8) Ideação em grupo. & 15 \\
\hline 9) Prototipagem. & 45 \\
\hline 10) Voltar ao campo para apresentar o protótipo e preencher o feedback do teste. & - \\
\hline 11) Melhorar o protótipo com base nas sugestões da comunidade. & 45 \\
\hline 12) Apresentação. & 5/equipe \\
\hline
\end{tabular}

Fonte: As autoras (2018).

Destaca-se a importância de planejar. Planejar é tarefa obrigatória do processo ensino e aprendizagem, pois ensinar pressupõe reflexão sistemática do fazer pedagógico. Além do "o que fazer" ou "o que ensinar", incluem-se o "como" e o "por que fazê-lo". Implica criticidade, autoavaliação, reavaliação, fuga do improviso. O planejamento ajuda a otimizar o tempo em sala, a antecipar os recursos didáticos e possíveis dúvidas dos alunos (SILVA, 2014).

\section{Considerações finais}

É muito importante, aos docentes, a percepção de que a educação ambiental é enquadrada por seu contexto social e centrada nas interações humanas com o mundo ao redor. Consequentemente, é papel do professor propor aos estudantes a se engajarem em diálogo produtivo e tomada de decisões que propiciem um meio ambiente equilibrado, o consumo responsável e a solidariedade equitativa. E isso é possível, por meio da utilização do Design Thinking o qual valoriza uma situação-problema como estratégia de ensino e aprendizagem, objetivando, inicialmente por meio da descoberta, uma formação ativa e emancipatória do estudante. 


\section{Referências}

ALARCÃO, I. Professores reflexivos em uma escola reflexiva. 8.ed. São Paulo: Cortez, 2011.

ANTUNES, C. Professores e professauros: reflexões sobre a aula e práticas pedagógicas diversas. 9. ed. Petrópolis: Vozes, 2014.

ARDOIN, N.M. Environmental Education: A Strategy for the Future. Palo Alto: Environmental Grantmakers Association, 2009.

AVANZI, M.R. Ecopedagogia. In: LAYRARGUES, P.P. (Coord.). Identidades da educação ambiental brasileira. Brasília: Ministério do Meio Ambiente, 2004.

BRASIL. Constituição (1988). Constituição da República Federativa do Brasil. Brasília, DF: Senado Federal: Centro Gráfico, 1988. 292 p.

BRASIL. Decreto no 4.281, de 25 de junho de 2002. Regulamenta a Lei no 9.795, de 27 de abril de 1999, que institui a Política Nacional de Educação Ambiental, e dá outras providências. Diário Oficial da república Federativa do Brasil. Brasília, DF, 26 junho de 2002. Disponível em: <http://www. planalto.gov.br/ccivil 03/decreto/2002/d4281.htm>. Acesso em: 15 mar. 2016.

BRASIL. Lei no 6.938, de 31 de agosto de 1981. Dispõe sobre a Política Nacional do Meio Ambiente, seus fins e mecanismos de formulação e aplicação e dá outras providências. Diário Oficial da república Federativa do Brasil. Brasília, DF, 2 set. 1981. Disponível em: <http://www.planalto.gov.br /ccivil 03/leis/l6938.htm>. Acesso em: 15 mar. 2015a.

BRASIL. Lei no 9.795, de 27 de abril de 1999. Dispõe sobre a educação ambiental, institui a Política Nacional de Educação Ambiental e dá outras providências. Diário Oficial da república Federativa do Brasil. Brasília, DF, 28 abr. 1999. Disponível em: <http://www.planalto.gov.br/ccivil 03 /leis/19795.htm>. Acesso em: 07 jul. 2015b.

BROWN, T.; WYATT, J. Design Thinking for Social Innovation. Stanford Social Innovation Review. Winter 2010, Volume 8, Number 1.

COSTA, J.M.; PINHEIRO, N.A.M. O ensino por meio de temas-geradores: a educação pensada de forma contextualizada, problematizada e interdisciplinar. Imagens da Educação, v. 3, n. 2, p. 37-44, 2013.

DIESEL, A.; BALDES, A.L.S.; MARTINS, S.N. Os princípios das metodologias ativas de ensino: uma abordagem teórica. Revista Thema, v. 14, n. 1, p. 268288, 2017.

ECHOS. Toolkit design thinking: Introdução. São Paulo: Echos - Laboratório de inovação, 2016.

EDUCADIGITAL, Instituto. Design thinking para Educadores. Versão em Português: Instituto Educadigital, 2013. Disponível em: $<$ http://issuu.com/dtparaeducadores>. Acesso em: 17 mai. 2018. 
FREIRE, P. Conscientização: teoria e prática da libertação - uma introdução ao pensamento de Paulo Freire. São Paulo: Cortez \& Moraes, 1979.

GUIMARÃES, M. Educação ambiental Crítica. In: LAYRARGUES, P.P. (Coord.). Identidades da educação ambiental brasileira. Brasília: Ministério do Meio Ambiente, 2004.

JACOBI, P. Educação Ambiental, Cidadania e sustentabilidade. Cadernos de Pesquisa, São Paulo. n. 118, p. 189-205, mar. 2003.

LAYRARGUES, P.P. A resolução de problemas ambientais locais deve ser um tema-gerador ou a atividade-fim da educação ambiental? In: REIGOTA, M. (Org.). Verde cotidiano: o meio ambiente em discussão. Rio de Janeiro: DP\&A Editora, 1999.

MINISTÉRIO DA EDUCAÇÃO. Resolução oㅡ 2, de 15 de junho de 2012. Estabelece as Diretrizes Curriculares Nacionais para a Educação Ambiental. Diário Oficial da república Federativa do Brasil. Brasília, DF, 18 junho de 2012. Disponível em: <http://conferenciainfanto.mec.gov.br/images /conteudo/iv-cnijma/diretrizes.pdf>. Acesso em: 14 mai. 2018.

MORAN, J. Por onde começar a transformar nossas escolas? Disponível em: <www2.eca.usp.br/moran>. Acesso em: 21 mai. 2018.

SILVA, S. 50 atitudes do professor de sucesso. Petrópolis: Vozes, 2014.

SOUSA, S.O. Aprendizagem Baseada em Problemas: estratégia para o ensino e aprendizagem de algoritmos e conteúdos computacionais. 2011. $251 \mathrm{f}$. Dissertação (mestrado) - Universidade Estadual Paulista, Faculdade de Ciências e Tecnologia, Presidente Prudente. 2011.

TOZONI-REIS. M.F.C. Temas ambientais como "temas geradores": contribuições para uma metodologia educativa ambiental crítica, transformadora e emancipatória. Educar, Curitiba, n. 27, p. 93-110, 2006. Editora UFPR, Curitiba, n. 27, p. 93-110, 2006. Editora UFPR.

VALLIM, M.B.R. Um modelo reflexivo para formação de engenheiros. 2008.169 f. Tese (Doutorado em Engenharia Elétrica) - Programa de Pós-Graduação em Engenharia Elétrica, Universidade Federal de Santa Catarina, Florianópolis. 2008.

VASCONCELLOS, C. Avaliação da aprendizagem: Práticas de mudança por uma práxis transformadora. São Paulo: Libertad, 2006.

VILAÇA, L.D. Interpretação e ideação - Design Thinking. Disponível em: <https://www.youtube.com/watch?v=RJ7y2uAJvxw>. Acesso em: 16 mai. 2018. 